\title{
Experimental assessment of an energy management strategy on a fuel cell hybrid vehicle
}

\author{
P.A. Veenhuizen, E. Tazelaar \\ P.A. Veenhuizen (corresponding author) HAN University of Applied Science, \\ PO Box 2217, 6802CE Arnhem, The Netherlands, bram.veenhuizen@han.nl
}

\begin{abstract}
Fuel cell hybrid power trains comprise an energy storage to supply peaks in the power demand and to facilitate regenerative braking. In terms of control systems, the presence of storage provides additional freedom to minimize the vehicle's fuel consumption. In a previous paper [1] an analytical solution to the energy management problem for fuel cell hybrid propulsion systems was derived and compared with existing strategies like the Equivalent Consumption Minimization Strategy (ECMS) [1-4]. An experimental study has been carried out on a Fiat Doblo, which was converted from a regular gasoline powered vehicle into a fuel cell hybrid vehicle. The fuel cell drive train comprises a 10kW proton exchange membrane fuel cell stack connected by means of a DC/DC converter to a Li-ion battery. The aforementioned analytical energy management strategy was used during the experiments. The experiments were carried out on a roller test bench and on the road. The experiments were conducted not only to validate the energy management strategy and the underlying models but also to establish its practical value. The paper shortly reviews the energy management problem and solution. Next the vehicle and its fuel cell hybrid drive train are presented as well as the experimental setup. The paper finishes by stating the experimental results and the conclusions.
\end{abstract}

Keywords: PEM fuel cell (proton exchange membrane), power management, hydrogen

\section{Introduction}

\subsection{Background}

The international interest in the electric vehicle is increasing rapidly, especially now that governments on both national and municipal level embrace its obvious benefits: zero local emissions and improved propulsion efficiency. Together with this growing interest comes the attention for the equally obvious limitations: dramatically reduced range and substantially higher cost compared with a conventional gasoline vehicle of the same class, long battery charging times and issues regarding battery durability. These limitations warrant a strong research interest for new solutions based on fuel cell technology. Fuel cell vehicles are almost invariably hybridized, meaning that a battery supplies peak power during ac- celerations and recuperates kinetic energy during braking. If the battery can be charged by grid power, the vehicle can be regarded as a plug in hybrid. An energy management system selects the split of the required drive power between fuel cell stack and battery on the basis of minimum fuel consumption.

\subsection{Goal of this study}

During the development of energy management strategies for fuel cell hybrid vehicles, it was decided to realize a test vehicle for model validation, functional testing of the EMS and the vehicle. The vehicle is not only used as a test platform for the hybrid fuel cell drive train and the EMS, but is ultimately intended for regular use by the municipality of Arnhem. The study this paper reports on was mainly focussed on the ex- 
perimental validation of the EMS, but should also give insight in the practical viability of the EMS, the hybrid drive train and the entire vehicle.

\subsection{Structure of the paper}

This paper describes in Section 2 the models used for the development of the energy management control loop. In Section 3 the test vehicle, the fuel cell system and the experiments and their results are presented. This Section also covers the operation of the EMS. Section 4 discusses the viability of the fuel cell hybrid drive train and vehicle for its intended purpose. The paper ends with conclusions and recommendations in Section 5.

\section{Energy management}

\subsection{Models}

The electrochemical structure of both fuel cells and batteries results in a comparable electrical behavior. Focussing on the electrical efficiency of both components, as first-principles quasistatic model of this behavior, an ideal voltage source with internal resistance in series is proposed $[2,3,5]$, as indicated in the fuel cell system topology of Fig. 1.

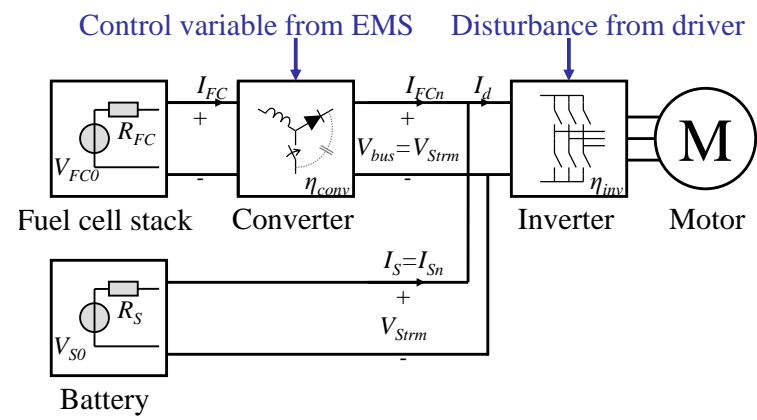

Figure 1: Topology of the fuel cell hybrid propulsion system.

The accompanying equations for both fuel cell stack and battery are:

$$
\begin{gathered}
V_{F C t r m}=V_{F C 0}-R_{F C} I_{F C} \\
V_{S t r m}=V_{S 0}-R_{S} I_{S},
\end{gathered}
$$

where $V_{F C O}$ and $V_{S 0}$ represent the internal ideal voltage sources, $R_{F C}$ and $R_{S}$ the internal resistance, $I_{F C}$ and $I_{S}$ the currents from the terminals and $V_{F C t r m}$ and $V_{\text {Strm }}$ the voltages at the terminals of fuel cell stack and battery respectively. In the considered topology, the voltage on the bus is defined by the battery voltage $V_{\text {bus }}=V_{\text {Strm }}$. Battery and fuel cell stack are interconnected using a DC/DC converter. The power losses in the converter are represented by an efficiency $\eta_{c n v}$.

$$
I_{F C n} V_{\text {bus }}=\eta_{\text {conv }} I_{F C} V_{F C t r m} .
$$

From an electrical point of view, the combination of fuel cell stack and converter act as a two-port with a nett current $I_{F C n}$ at its terminals. The ratio $r$ between this nett current $I_{F C n}$ and the fuel cell stack current $I_{F C}$ relates to the voltages and converter efficiency as:

$$
\begin{aligned}
r & =\eta_{\text {conv }} \frac{V_{F C t r m}}{V_{\text {bus }}} \\
& =\eta_{\text {conv }} \frac{V_{F C 0}-I_{F C} R_{F C}}{V_{S 0}-I_{S} R_{S}} .
\end{aligned}
$$

When deviations in both battery voltage and fuel cell stack voltage are considered relatively small, and considering the average battery current has to be zero to avoid overcharging or depleting the battery, ratio $r$ is approximated by:

$$
r \approx \eta_{\text {conv }} \frac{V_{F C 0}-\overline{I_{F C}} R_{F C}}{V_{S 0}} .
$$

With this approximation, ratio $r$ is considered a constant in the optimization problem of the energy management strategy.

\subsection{Energy Management Strategy}

The considered energy management strategy belongs to the class of optimizing strategies. Optimizing strategies proposed in literature minimize the fuel consumption directly [2-4]. The strategy considered in this study follows an alternative approach to obtain a minimum fuel consumption: it minimizes the losses in the system. A more detailed description of this approach can be found in [1].

Based on the models of Section 2.1, the losses are expressed as cost function (6)

$$
J\left(I_{F C}\right)=\int_{t=0}^{t_{\text {final }}} I_{F C}{ }^{2} R_{F C}+I_{S}^{2} R_{S} d t .
$$

This cost function includes the dominant losses in the fuel cell stack and the battery and through the constraints the converter efficiency. The cost function is subject to two constraints; the current to the inverter, demanded by the driver, should be met (7) and the time-average value of the battery current $I_{S}$ should be zero (8) to avoid overcharge or depletion

$$
\begin{gathered}
I_{S}+r I_{F C}=I_{d} \\
\int_{t=0}^{t_{\text {final }}} I_{S} d t=0 .
\end{gathered}
$$

To find the control variable $I_{F C}$ that minimizes the cost function, the first equality constraint is used to reduce the number of variables and the 
second constraint extends the cost function to a Lagrangian:

$$
\begin{aligned}
& L\left(I_{F C}\right)= \\
& \int_{t=0}^{t_{\text {final }}} I_{F C}{ }^{2} R_{F C}+\left(I_{d}-r I_{F C}\right)^{2} R_{S} d t \\
& \quad+\lambda \int_{t=0}^{t_{\text {final }}}\left(I_{d}-r I_{F C}\right) d t .
\end{aligned}
$$

The Optimality Principle of Bellman [6,7] provides the next reduced Lagrangian $L^{\prime}$ :

$$
\begin{aligned}
L^{\prime}\left(I_{F C}\right)=I_{F C} R_{F C} & +\left(I_{d}-r I_{F C}\right)^{2} R_{S} \\
& +\lambda\left(I_{d}-r I_{F C}\right) .
\end{aligned}
$$

As necessary and sufficient condition for minimum losses, it suffices to make the derivative of the reduced Lagrangian $L^{\prime}$ towards control variable $I_{F C}$ zero. By choosing a constant Lagrange multiplier to enable real-time implementation, the analytical solution $I_{F C}^{*}$ is derived as

$$
I_{F C}^{*}=\frac{1}{r} \overline{I_{d}}+\frac{r R_{S}}{R_{F C}+r^{2} R_{S}} \Delta I_{d}
$$

Here, $\Delta I_{d}$ refers to the difference between the average and actual current demand, $\Delta I_{d}=I_{d}-$ $\overline{I_{d}}$. The solution $I_{F C}^{*}$ found, calculated by the EMS, represents the signal to the DC/DC converter.

Typical to this solution is that the point of operation $I_{F C 0}$ for the fuel cell stack relates to the average current demand where the deviations from the point of operation are defined by the ratio in internal resistances of both fuel cell stack and battery.

Also the power consumption of the auxiliaries can be considered as loss. The current to the auxiliaries is dominated by the air compressor which has to provide an oxygen molecule for each two hydrogen molecules. Therefore, the current to the auxiliaries is considered linear with the stack current as:

$$
I_{\text {aux }}=\gamma I_{F C}+I_{\text {aux } 0} .
$$

Including the auxiliary current results in the next optimal solution

$$
\begin{aligned}
I_{F C}^{*} & =I_{F C 0}+\Delta I_{F C} \\
I_{F C 0} & =\frac{1}{r-\gamma}\left(\overline{I_{d}}+I_{\text {aux } 0}\right) \\
\Delta I_{F C} & =\text { ratio } \cdot \Delta I_{d}
\end{aligned}
$$

where

$$
\text { ratio }=\frac{(r-\gamma) R_{S}}{R_{F C}+(r-\gamma)^{2} R_{S}} .
$$

\subsection{Implementation}

The optimal solution of (13) still needs a-priori knowledge to determine the future average current demand $\overline{I_{d}}$. As causal solution, the average over the past is taken. This value is derived from observing long term deviations in the SOC of the battery: when the SOC drifts away over time, the average stack current is too high or too low. This is covered by a slow feedback loop on the SOC, which determines the point of operation for the fuel cell stack. This feedback path prevents overcharging or depleting the battery and adds robustness against model errors, parameter deviations, and poor SOC estimations. Based on this feedback loop, optimal solution (13) is implemented with a feedback and feed forward path as indicated in Fig. 2.

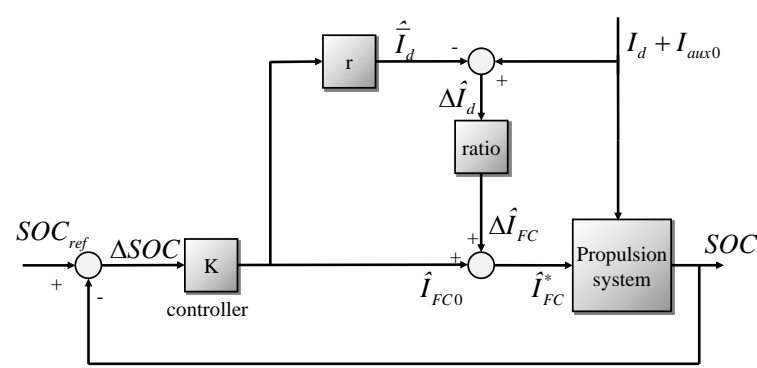

Figure 2: Optimal solution implemented as control loop.

As controller a proportional gain $P$ suffices [1]. With respect to the violation of the maximum currents for fuel cell stack and battery, it can be demonstrated that, when the optimal solution is out of range, the closest feasible value, provides the best solution given the bounds. Also with respect to bounded rates for the fuel cell system, most likely caused by the response time of the air compressor, the closest possible rate provides the best solution.

\section{Experimental validation}

\subsection{Test vehicle}

The energy management strategy, described in Section 2.2 was implemented in the Fiat Doblo test vehicle, shown in Fig. 3. This vehicle was converted from a regular gasoline drive line to an electric drive line by mounting an asynchronous motor onto the gear box after removing the engine. Both brake vacuum and hydraulic pressure for power steering are supplied by means of 12 $\mathrm{V}$ electric powered pumps. The main battery was mounted beneath the cargo area floor. The vehicle was also equipped with a charger, allowing it to be charged from a mains supply. Subsequently, the proton exchange membrane fuel cell system including the hydrogen tank, the power electronics and controller hardware were integrated in the cargo area of the vehicle. The bat- 


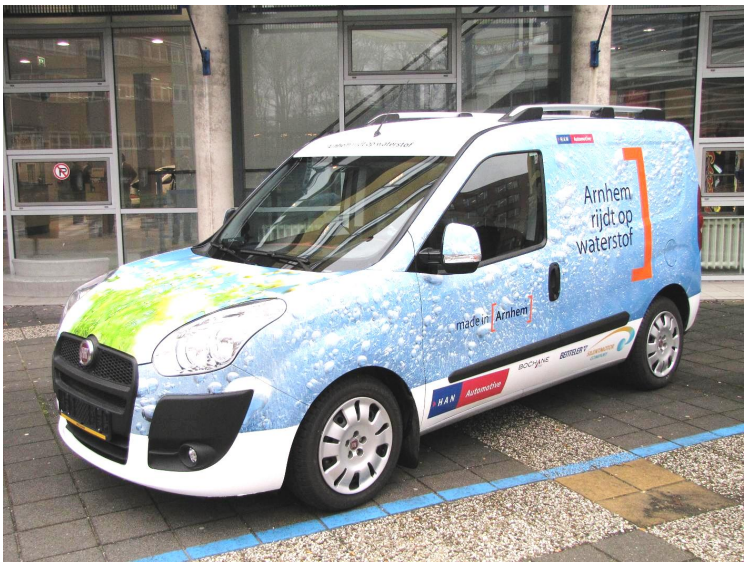

Figure 3: Fiat Doblo test vehicle.

tery voltage determines the bus voltage. This bus not only supplies power to the main drive inverter, but also to the auxiliary systems. A 12 $\mathrm{V}$ DC/DC converter is used to charge the standard vehicle battery and a $24 \mathrm{~V} \mathrm{DC/DC}$ converter supplies power to the fuel cell balance of plant and the main DC/DC converter (see Fig. 5). The main parameters of the Fiat Doblo hybrid power train are given in table 1 .

Table 1: Main parameters of the Fiat Doblo hybrid power train.

\begin{tabular}{lll}
\hline Description & Value & units \\
\hline Vehicle weight & 1675 & $\mathrm{~kg}$ \\
Vehicle top speed & 105 & $\mathrm{~km} / \mathrm{h}$ \\
Effective frontal area $C_{d} A$ & 1.35 & $\mathrm{~m}^{2}$ \\
Number of Fuel Cells & 75 & - \\
Maximum stack power & 10.5 & $\mathrm{~kW}$ \\
Maximum stack current & 230 & $\mathrm{~A}$ \\
Stack internal resistance & 77 & $\mathrm{~m} \Omega$ \\
Number of battery cells & 32 & - \\
Battery Voltage & 108 & $\mathrm{~V}$ \\
Battery Capacity & 180 & $\mathrm{Ah}$ \\
Battery c-rate & 3 & $\mathrm{~A} / \mathrm{Ah}$ \\
Battery internal resistance & 22.4 & $\mathrm{~m} \Omega$ \\
Tank storage capacity & 1.8 & $\mathrm{~kg} @ 350$ bar \\
Maximum motor power & 30 & $\mathrm{~kW}$ \\
\hline
\end{tabular}

\subsection{Fuel cell system}

The fuel cell system comprises a fuel stack manufactured by Nedstack bv. The stack consists of 75 cells. The Piping and Instrumentation Diagram (P\&ID) of the fuel cell system is given in Fig. 4. This figure shows the layout for the fuel cell system, comprising the stack, an intake air humidifier, a compressor (air pump), a hydrogen pump and a two stage cooling system. The

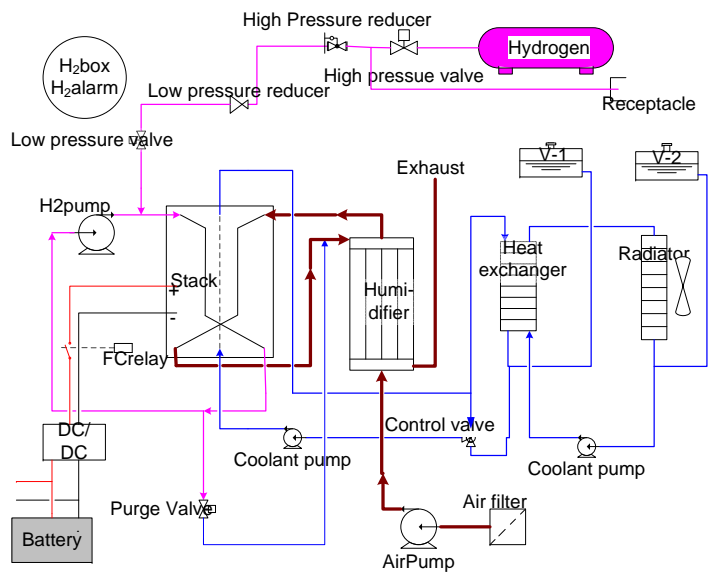

Figure 4: P\&ID of the fuel cell power system of the Fiat Doblo.

$\mathrm{DC} / \mathrm{DC}$ converter is used to control the current supplied to the power bus (see also Fig. 1).

\subsection{Control parameters}

The parameter values for the control loop shown in Fig. 2 used during testing can be found in table 2. The internal resistances $R_{F C}$ and $R_{S}$ of fuel

Table 2: Parameters values for the control loop

\begin{tabular}{lll}
\hline Symbol & Value & Units \\
\hline$R_{S}$ & 22.4 & $\mathrm{~m} \Omega$ \\
$R_{F C}$ & 77 & $\mathrm{~m} \Omega$ \\
$r$ & 0.51 & - \\
$\gamma$ & 0 & - \\
$P$ & 7.2 & $\mathrm{~A} / \%$ \\
\hline
\end{tabular}

cell stack and battery and the conversion ratio $r$ of the DC/DC converter determine that ratio = $14 \%$. This implies that $14 \%$ of the deviations in the power demand are provided by the fuel cell stack and the majority of $86 \%$ of the deviations are covered with the battery.

\subsection{Experiments}

The vehicle described in Section 3.1 was subjected to a number of extensive tests on a roller test bench. This test bench is capable of simulating the vehicle inertial mass by using a proper set of flywheels, thereby allowing for the simulation of regenerative braking. During these tests all major electric power flows were measured, by measuring battery $\left(U_{b a t}\right)$ (bus) and fuel cell stack voltage $\left(U_{F C}\right)$ and all relevant currents, as indicated in Fig. 5, which refers to the current sensors in the vehicle. Next, the translation from these measured values to the variables necessary for the energy management strategy are 


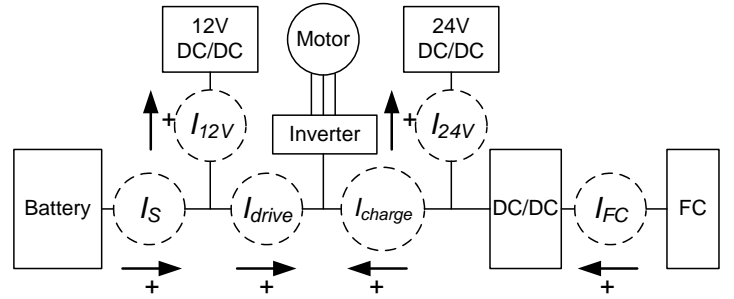

Figure 5: Current measuring positions and their labels, indicated by dashed circles.

discussed. Current to the inverter $I_{d}$ was determined by $I_{d}=I_{\text {charge }}+I_{\text {drive }}$ and the output current of the DC/DC converter is given by $I_{F C n}=I_{\text {charge }}+I_{24 \mathrm{~V}}$.

Additionally, the speed of the electric motor and the battery state of charge (SOC) were determined from CAN bus signals. During the tests, the transmission was kept in a fixed $\left(3^{\text {rd }}\right)$ gear. Measurements were carried out during test runs, following driving cycle speed profiles. Both the low power NEDC and a speed profile measured on the public road (referred to as the "Doornenburg" cycle) were used (see Table 3 ).

Table 3: Test cycle characteristics

\begin{tabular}{lccl}
\hline & $\begin{array}{c}\text { low power } \\
\text { NEDC }\end{array}$ & $\begin{array}{c}\text { "Doornen- } \\
\text { burg" }\end{array}$ & Units \\
\hline Duration & 1020 & 2050 & $\mathrm{sec}$ \\
Distance & 9.9 & 21.6 & $\mathrm{~km}$ \\
Max. speed & 90 & 80 & $\mathrm{~km} / \mathrm{h}$ \\
\hline
\end{tabular}

\subsection{Measurement results}

\subsubsection{Low power NEDC cycle}

Fig. 6b shows the power at three branches in the drive train, measured during a NEDC low power run. During this measurement $S O C_{r e f}=90 \%$ was selected. Negative values for $P_{d}$ indicate brake energy recovery. The peak drive power demand is close to the peak power $(30 \mathrm{~kW})$ of the drive motor. The fuel cell stack power $P_{F C}$ varies between 5 and $8 \mathrm{~kW}$, whereas the battery power $P_{S}$ supplies the majority of the dynamic load. This behavior of the controller was described in Section 3.3.

Inspection of Fig. 7b shows that during city cycle driving, $(t<860 \mathrm{sec})$, the $S O C$ remains fairly constant with a steady state error of about $S O C_{r e f}-S O C=15 \%$. Driving the extra-urban part of the cycle discharges the battery, causing the SOC to drop and the operating point $I_{F C 0}$ to rise. Fig. $7 \mathrm{~b}$ shows that the stack current $I_{F C}$ follows the optimal current $I_{F C}^{*}$ very well. It should be noted here that the maximum steady
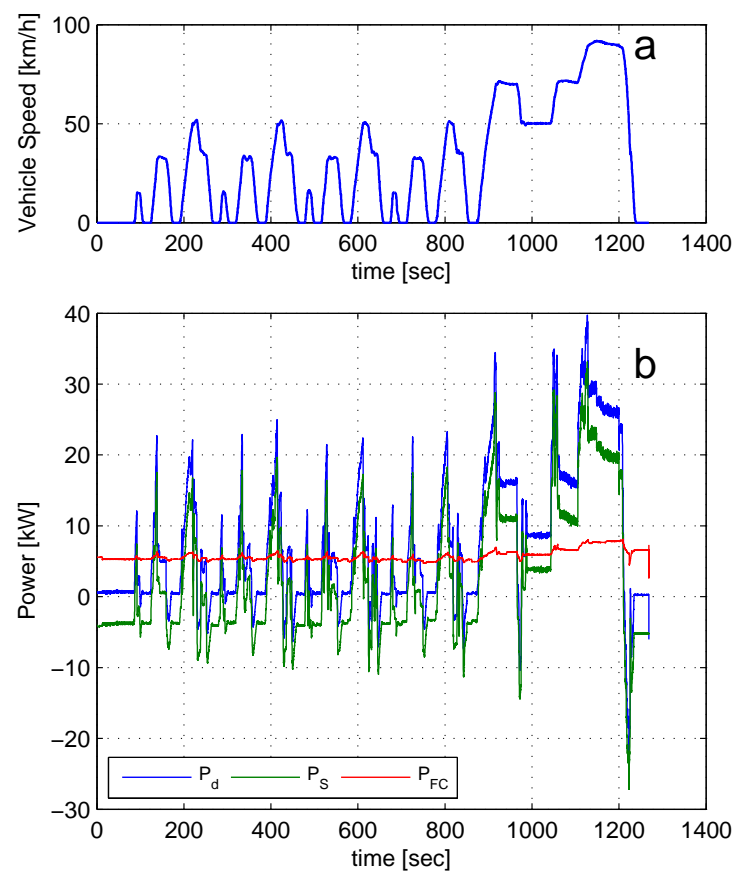

Figure 6: The NEDC low power driving cycle (a) and corresponding power levels (b) of drive power $P_{d}$, battery power $P_{S}$ and fuel cell stack power $P_{F C}$.

state error in the $S O C$ that arises at full fuel cell power $\left(10.5 \mathrm{~kW}\right.$ at $\left.I_{F C}=230 \mathrm{~A}\right)$ will be $32 \%$. Since too low $S O C$ should be avoided in order to prevent battery damage, the setpoint $S O C_{r e f}$ should be kept higher than the minimum allowable SOC increased with $32 \%$. Another approach might be the addition of a bias in the controller of Fig. 2. The rather small value for ratio leads to the small influence of $\Delta I_{d}$ on $I_{F C}^{*}$. The remaining part of $\Delta I_{d}$ must be supplied by the battery. Since the sizing of the battery is mainly determined by its power rating, this means that the battery can be sized a factor 1 - ratio smaller compared to the case where the battery would be the only power source to provide the transients in the power demand.

\subsection{2 "Doornenburg" Cycle}

The "Doornenburg" cycle speed profile and some power levels are depicted in Fig. 8 and the accompanying. Fig. 9 shows the SOC and the control loop signals. During this measurement $S O C_{r e f}=65 \%$ was selected. Fig. $8 \mathrm{~b}$ shows that the average fuel cell stack power increases slowly during the first phase of the cycle $(t<$ $1200 \mathrm{sec}$ ) to level off at about $6 \mathrm{~kW}$. This power increase is associated with a gradual decrease of $S O C$ witnessed in Fig. 9a. Zooming in on the data, as shown in Fig. 10, reveals that the limited positive slew rate of the fuel cell stack sys- 

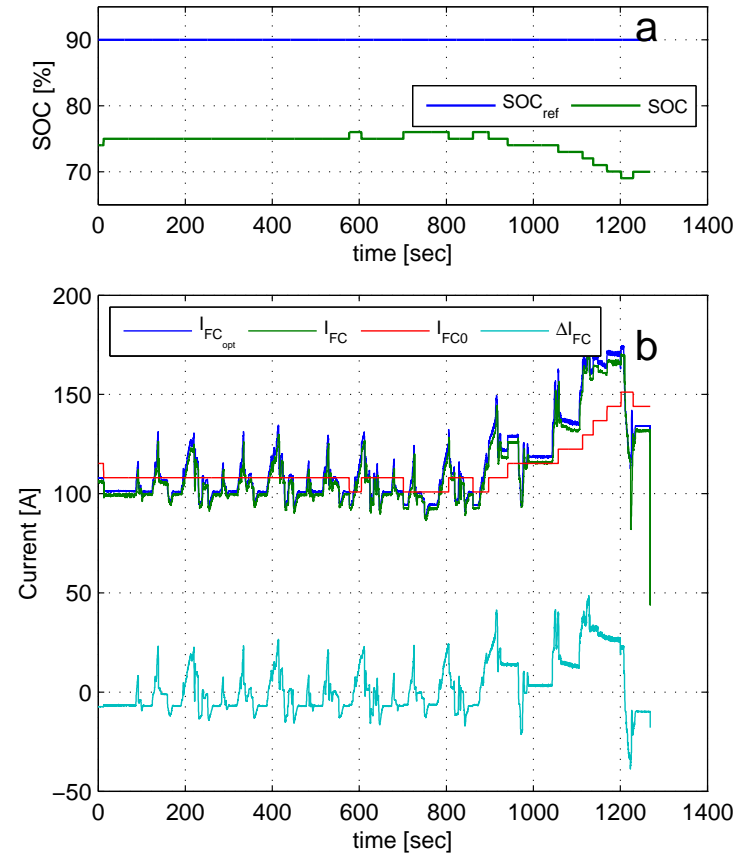

Figure 7: SOC (a) and currents (b) as control loop signals (see Fig. 2), determined during a NEDC low power driving cycle run.

tem, which is caused by the limited dynamic response of the compressor, causes some deviation between $I_{F C}^{*}$ and $I_{F C}$. This will have a minor effect on the optimal fuel consumption and still leads to the optimal solution, given the hardware limitations, as explained in Section 2.3.

\section{Discussion}

Fig. 10b shows that the stack is capable to supply sufficient power to this vehicle to drive the "Doornenburg" cycle, a suburban cycle regarded as typical for the vehicles intended use. Typical values for the electric power consumed during the low power NEDC and the "Doornenburg" cycle are summarized in table 4 . These values

Table 4: Electric power consumption in $\mathrm{Wh} / \mathrm{km}$.

\begin{tabular}{lcc}
\hline & $\begin{array}{c}\text { low power } \\
\text { NEDC }\end{array}$ & $\begin{array}{c}\text { "Doornen- } \\
\text { burg" }\end{array}$ \\
\hline 12 V converter & 17 & 17 \\
24 V converter & 13 & 10 \\
drive motor & 242 & 205 \\
\hline Total & 272 & 232 \\
\hline
\end{tabular}

show that about $10 \%$ of the electric power is
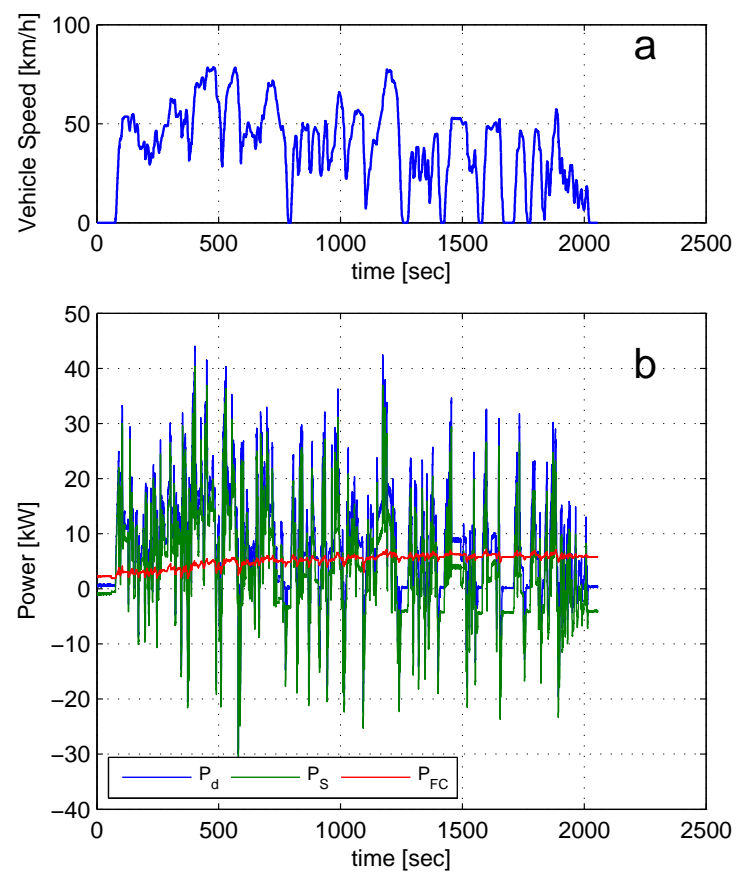

Figure 8: Power levels (b) measured during a "Doornenburg" driving cycle run (a).

consumed by the auxiliaries. The total power consumption is in reasonable agreement with literature values for a vehicle with comparable weight [8].

Since every hydrogen atom produces two electrons, based on the current drawn from the stack, an estimate of the hydrogen consumption can be made by using the equation: $\dot{m}=$ $N_{\text {cells }} I_{F C} M /(2 F)$, where $N_{\text {cells }}$ equals the number of cells in the stack, $M$ equals the molar mass of hydrogen and $F$ is the Faraday constant. The low power NEDC and the "Doornenburg" cycle lead to hydrogen consumption of about $1.1 \mathrm{~kg} / 100 \mathrm{~km}$ and $0.85 \mathrm{~kg} / 100 \mathrm{~km}$, respectively. Purging losses have been neglected here.

\section{Conclusions and recommenda- tions}

The energy management strategy proposed in [1] was tested on a roller test bench with a fully functional fuel cell hybrid vehicle. Tests were conducted by running the vehicle over the low power NEDC and a typical suburban cycle. Measurement of all main power flows in the drive line were carried out. The measurements validate the practical viability of the proposed EMS by showing that the fuel cell system does stabilize the $S O C$ of the battery.

The energy management strategy causes a de- 

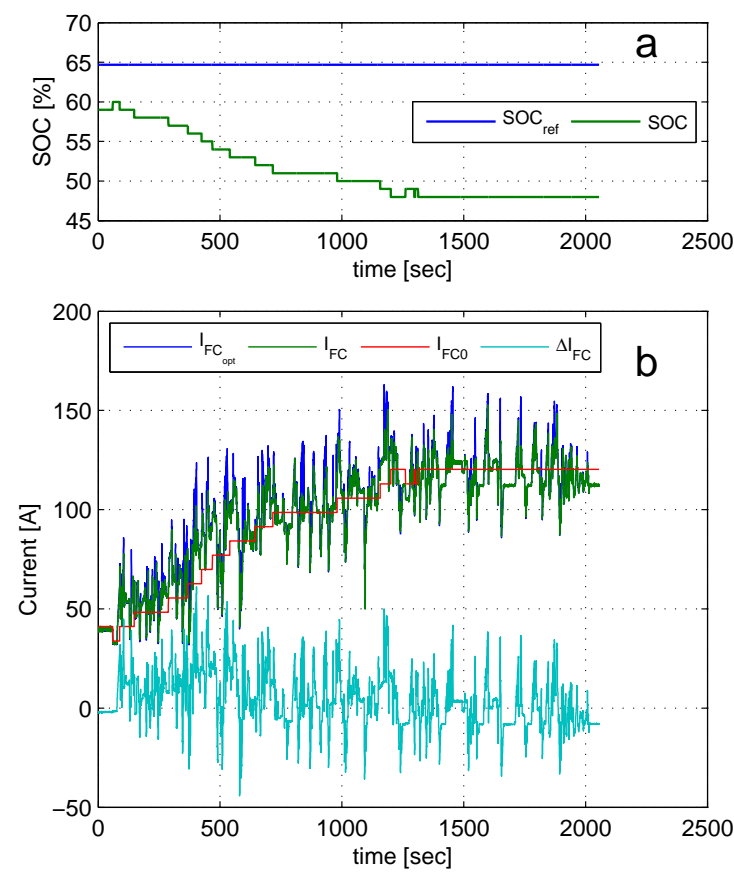

Figure 9: SOC (a) and currents (b) as control loop signals (see Fig. 2), determined during a "Doornenburg" driving cycle run.

fined power split between fuel cell stack and battery. This power split has important consequences for the sizing of the battery. The extensive vehicle testing shows that the vehicle can be expected to perform adequately as far as its electric power consumption is concerned. Further work on thermal management must be carried out.

\section{Acknowledgments}

This work was financially supported by the municipality of Arnhem, province of Gelderland, the Dutch state and the HAN University of Applied Science. The support by staff of Silent Motor Company is gratefully acknowledged.

\section{References}

[1] Tazelaar E., Veenhuizen P.A., van den Bosch P.P.J., Grimminck M., Analytical solution and experimental validation of the enrgy management problem for fuel cell hybrid vehicles, proc. EEVC, Brussels, 2011

[2] Koot M., Kessel J.T.B.A., de Jager B., Heemels W.P.M.H., van den Bosch P.P.J., Steinbuch M., Energy Management Strategies for Vehicular

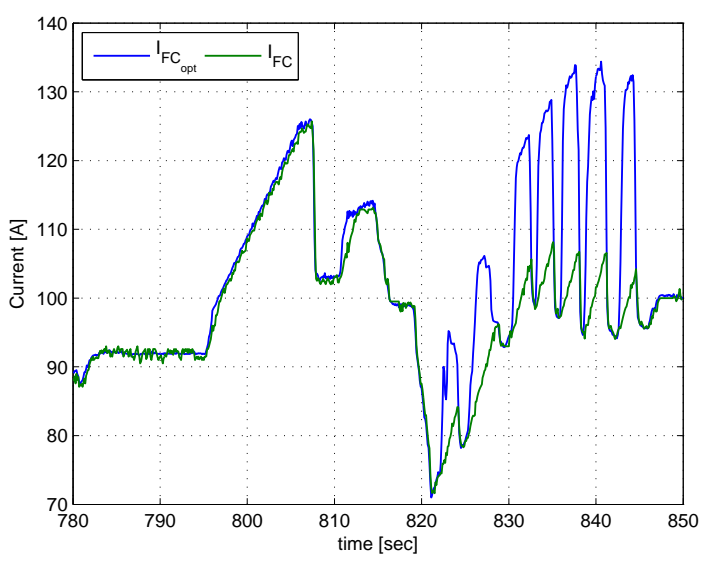

Figure 10: Control loop signals determined during a "Doornenburg" driving cycle run. Detail of Fig. 9b.

Electric Power Systems, IEEE trans. Vehicular Technology, 2005

[3] Kessels J.T.B.A., Koot M.W.T., van den Bosch P.P.J., Kok D.B., Online Energy Management for Hybrid Electric Vehicles, IEEE trans. on Vehicular Technology, 2008

[4] Tazelaar E., Veenhuizen P.A., van den Bosch P.P.J., Analytical solution of the energy management for fuel cell hybrid propulsion systems, IEEE trans. Vehicular Technology, accepted for publication, 2012

[5] Guzzella L., Sciarretta A., Vehicle propulsion systems, introduction to modeling and optimization, Springer, 2005

[6] Bellman R., Dynamic programming, Princeton University Press, 1957

[7] Kirk D.E., Optimal Control Theory; An Introduction, Dover Publications, 1988

[8] Besselink, I.J.M. Hereijgers, J.A.J. van Oorschot, P.F. Nijmeijer, H. Evaluation of $20000 \mathrm{~km}$ driven with a battery electric vehicle, proc. EEVC, Brussels, 2011 


\section{Authors}

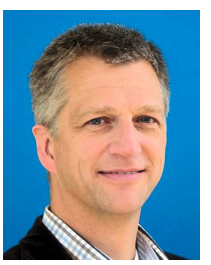

Bram Veenhuizen received his $\mathrm{PhD}$ degree on from the University of Amsterdam in 1988. He joined SKF focussing on electromagnetic and X-ray techniques to characterize materials and material fatigue. In 1995 he joined van Doornes Transmisie, where he was responsible for the realization of some advanced drive train projects. In 2002 he was appointed assistant professor at the Eindhoven University of Technology. Since 2005 he is professor in vehicle mechatronics at the HAN University of Applied Sciences.

Edwin Tazelaar received his masters degree in Electrical Engineering from the Eindhoven University of Technology in 1992. He worked in the fields of control systems, power plants and high power semiconductors for KEMA and Philips Semiconductors. Currently he is researcher on fuel cell based propulsion systems and manager of the Master program Control Systems Engineering, at the HAN University of Applied Sciences in Arnhem, the Netherlands. 